[6] Amstalden EM, Xavier R, Kattapuram SV, et al. Paracoccidioidomycosis of bones and joints. A clinical, radiologic, and pathologic study of 9 cases. Medicine (Baltimore) 1996; 75:213-25.

[7] Nogueira SA, Guedes AL, Wanke B, et al. Osteomyelitis caused by Paracoccidioides brasiliensis in a child from the metropolitan area of Rio de Janeiro. J Trop Pediatr 2001;47:311-5.

[8] Nogueira MG, Andrade GM, Tonelli E. Clinical evolution of paracoccidioidomycosis in 38 children and teenagers. Mycopathologia 2006;161: 73-81.

Edson Marchiori ${ }^{\mathrm{a}, \mathrm{b}, *}$ Marcos Dalston ${ }^{\mathrm{a}, \mathrm{c}}$ Gláucia Zanetti ${ }^{\mathrm{b}, \mathrm{d}}$

Bruno Hochhegger ${ }^{\mathrm{b}, \mathrm{e}}$

a Fluminense Federal University, Rio de Janeiro, Brazil ${ }^{\mathrm{b}}$ Federal University of Rio de Janeiro, Rio de Janeiro,

Brazil

${ }^{\mathrm{c}}$ Rua Marques do Paraná, 530, Centro Niterói, CEP 24220.011, Niterói, Rio de Janeiro, Brazil d Rua Coronel Veiga, 733, Apto 504, Centro, CEP 25655-504, Petrópolis, Rio de Janeiro, Brazil

e Rua João Alfredo, 558/301, CEP 90050-230, Porto Alegre, Brazil

* Corresponding author. Rua Thomaz Cameron, 438, Valparaiso, CEP 25685.120, Petrópolis, Rio de Janeiro, Brazil. Tel.: +55 24 22492777; fax: $+55(21) 26299017$.

E-mail addresses: edmarchiori@gmail.com (E. Marchiori), marcos.dalston@yahoo.com.br

(M. Dalston), glauciazanetti@gmail.com

(G. Zanetti), brunohochhegger@gmail.com

(B. Hochhegger)

5 January 2011

Available online 7 March 2012

doi:10.1016/j.jbspin.2011.01.015

\section{Power Doppler ultrasonographic evaluation of enthesitis in psoriatic arthritis. A multi-center study}

\section{A R T I C L E I N F O}

\section{Keywords:}

Ultrasonography

Power Doppler

Enthesitis

Psoriatic arthritis

Enthesitis represents a frequent abnormality in psoriatic arthritis (PsA). The involvement of peripheral entheses can be asymptomatic and underestimated by clinical examination and can be detected only by imaging techniques [1,2]. Recently, ultrasound (US) has demonstrated to be a valuable tool in the assessment of entheseal involvement in spondylarthropathies ( $\mathrm{SpA}$ ), providing depiction of entheseal abnormalities at all stages of the disease process $[1,3-5]$. However, only limited focus on extensive evaluation of peripheral enthesitis in PsA by US has been developed, so far. Thus, by using US combined with power Doppler (PD) and including both assessment of inflammatory changes and structural alterations, the aims of the present study were to investigate the prevalence and severity of peripheral entheses involvement in PsA and to compare PDUS-detected findings with clinical and laboratory data.

\section{Methods}

Consecutive PsA patients and rheumatoid arthritis (RA) controls were included in a multi-center prospective study. In each rheumatology unit, patients underwent clinical examination, laboratory tests and PDUS examination (Logiq9/Logiq5 GE machine; 8-15 MHz linear probe) of major entheses at both extremities. Previously to patients' enrolment, the US examination methodology was clarified among sonographers and a consensus was obtained on scanning protocol and image interpretation. By using the OMERACT definition for enthesopathy [6], different elementary lesions were assessed by PDUS and scored either on a semi-quantitative $(0-3)$ or a dichotomous (0-1) scale. The sums of the local scores at single entheseal sites and at a global entheseal level (global entheseal PDUS score) were calculated. The following entheses were examined bilaterally: common extensor tendon at its insertion at the lateral humeral epicondyle; gluteus tendons at their insertion at the greater trochanter; quadriceps tendon at its insertion at the superior pole of the patella; patellar tendon at its proximal insertion at the inferior pole of the patella; patellar tendon at its distal insertion at the tibia tuberosity; Achilles tendon at its insertion at the calcaneus; plantar aponeuroses at its insertion at the calcaneus.

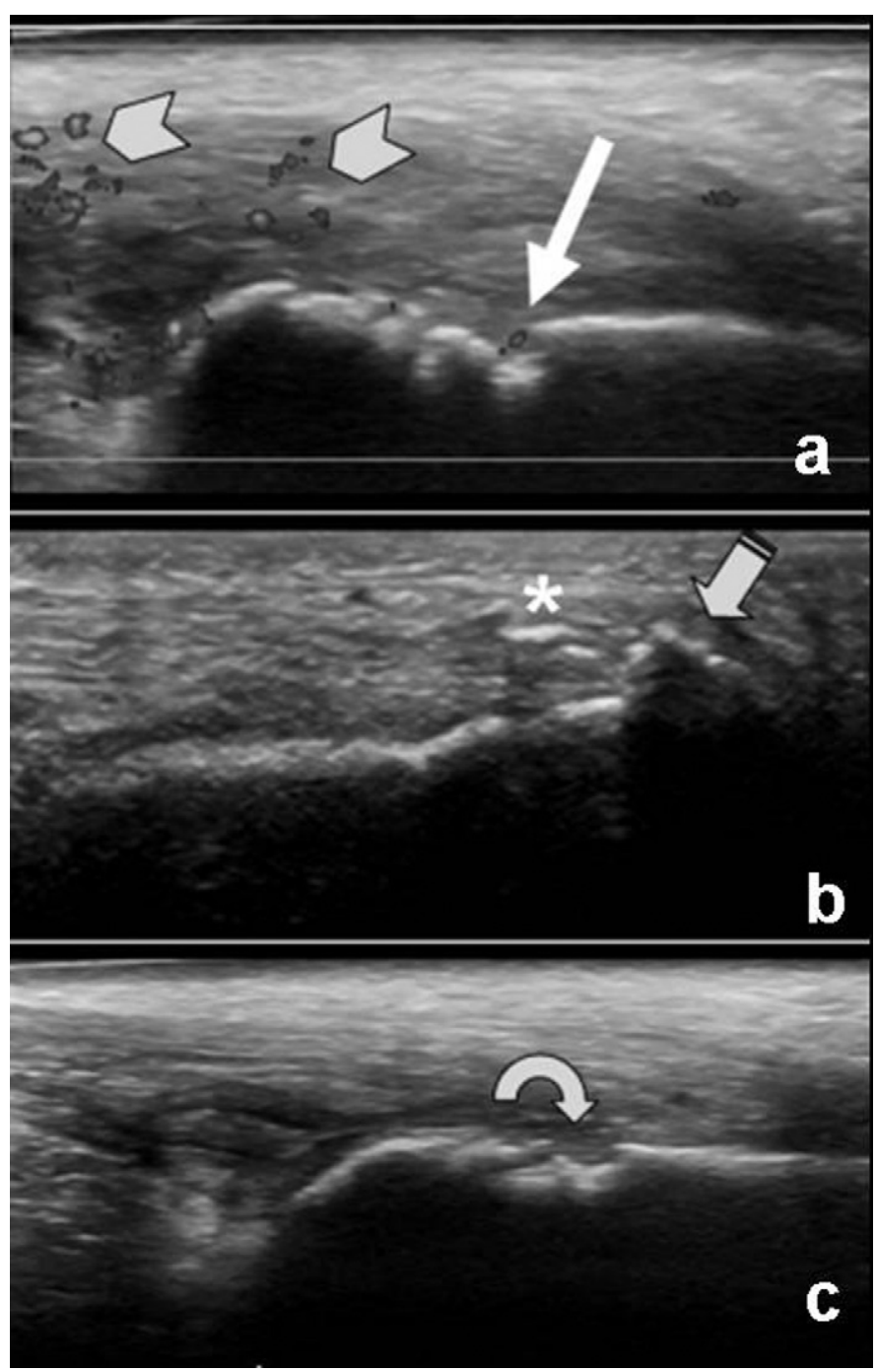

Fig. 1. PDUS of the Achilles tendon enthesis. Longitudinal scan. a: power Dopple signal at the enthesis level (arrow) and at the tendon level (arrowhead); b: presence of an enthesophyte (arrow) and calcifications $\left({ }^{*}\right)$; c: evidence of calcaneal bone erosions (curved arrow). 
Table 1

Basic PDUS findings at all the entheseal sites examined in PsA and RA patients: prevalence, percentage (\%) and grade (mean $\pm 95 \% \mathrm{CI})$.

\begin{tabular}{|c|c|c|c|c|c|c|}
\hline \multirow[b]{2}{*}{ Basic PDUS findings } & \multicolumn{2}{|c|}{$\begin{array}{l}\text { Prevalence and percentage (\%) of basic } \\
\text { PDUS findings }\end{array}$} & \multirow[t]{2}{*}{$P$} & \multicolumn{2}{|c|}{ Grade of basic PDUS findings (mean $\pm 95 \% \mathrm{CI}$ ) } & \multirow[t]{2}{*}{$P$} \\
\hline & PsA & RA & & PsA & RA & \\
\hline Hypoechogenicity & $178(16.7 \%)$ & $14(3.8 \%)$ & 0.0000001 & $0.2 \pm 0.02$ & $0.04 \pm 0.02$ & 0.0001 \\
\hline Thickening & $72(6.8 \%)$ & $19(5.2 \%)$ & n.s & $0.1 \pm 0.01$ & $0.05 \pm 0.02$ & n.s \\
\hline Calcifications & $202(19 \%)$ & $31(8.5 \%)$ & 0.000003 & $0.3 \pm 0.04$ & $0.1 \pm 0.04$ & 0.0001 \\
\hline Enthesophytes & $391(36.8 \%)$ & $107(29.4 \%)$ & 0.011 & $0.5 \pm 0.04$ & $0.4 \pm 0.08$ & n.s \\
\hline Erosions & $67(6.3 \%)$ & $5(1.4 \%)$ & 0.0002 & $0.08 \pm 0.02$ & $0.01 \pm 0.01$ & 0.0001 \\
\hline Bony irregularity & $126(11.8 \%)$ & $53(14.6 \%)$ & n.s & $0.12 \pm 0.01$ & $0.15 \pm 0.03$ & n.s \\
\hline PD signal enthesis & $49(4.6 \%)$ & $4(1.1 \%)$ & 0.002 & $0.07 \pm 0.02$ & $0.01 \pm 0.01$ & 0.002 \\
\hline PD signal tendon & $64(6 \%)$ & $12(3.2 \%)$ & 0.046 & $0.1 \pm 0.02$ & $0.03 \pm 0.2$ & 0.009 \\
\hline Bursitis & $86(8.1 \%)$ & $27(7.4 \%)$ & n.s & $0.01 \pm 0.02$ & $0.08 \pm 0.03$ & n.s \\
\hline Tendon lesion & $5(0.5 \%)$ & $1(0.3 \%)$ & n.s & $0.04 \pm 0.03$ & $0.027 \pm 0.005$ & n.s \\
\hline
\end{tabular}

PDUS: power Doppler ultrasound; PsA: psoriatic arthritis; RA: rheumatoid arthritis; CI: confidence interval; PD: power Doppler.

\section{Results}

One thousand and sixty-four entheses of 76 PsA patients and 224 of 26 RA controls were examined. The global number of entheses with PDUS-detected abnormalities (Fig. 1) were 756 in PsA patients and 224 in controls $(P=0.0008)$. At enthesis level, the prevalence and grade of most inflammatory and structural damage lesions (Table 1) resulted to be significantly higher in PsA than in RA $(P<0.0000001$ and 0.01 respectively). The global entheseal PDUS score showed a more serious involvement in PsA than in controls $(22.77 \pm 18.8$ vs $14.04 \pm 9.8 ; P=0.03)$. Poor significant correlations were demonstrated between global entheseal PDUS score and MASES $(P<0.033)$. The analysis of the findings at patient level didn't give results able to discriminate between RA and PsA patients.

\section{Discussion}

This is the first study showing PDUS findings indicative of extensive and severe entheseal abnormalities, related both to inflammation and structural damage, in PsA. Enthesitis, a typical pathological feature of SpA, may assume variable aspects and different locations [7-9]. However, due to the low sensitivity of clinical assessment in the detection of inflammatory musculoskeletal changes, peripheral enthesitis is frequently mixed up with other joint and soft tissues disorders by physical examination and its presence may be often underestimated [1]. Therefore, imaging modalities, such as musculoskeletal US, play a fundamental role in this field helping in the detection of various entheseal abnormalities at different entheseal sites.

\section{Disclosure of interest}

The authors declare that they have no conflicts of interest concerning this article.

\section{References}

[1] D'Agostino MA, Said-Nahal R, Hacquard-Bouder C, et al. Assessment of peripheral enthesitis in the spondylarthropathies by ultrasonography combined with power Doppler: a cross-sectional study. Arthritis Rheum 2003;48:523-33.

[2] Riente L, Delle Sedie A, Filippucci E, et al. Ultrasound imaging for the rheumatologist IX. Ultrasound imaging in spondyloarthritis. Clin Exp Rheumatol 2007;25:349-53.

[3] Filippucci E, Aydin SZ, Karadag O, et al. Reliability of high-resolution ultrasonography in the assessment of Achilles tendon enthesopathy in seronegative spondyloarthropathies. Ann Rheum Dis 2009;68:1850-5.

[4] Balint PV, Kane D, Wilson $\mathrm{H}$, et al. Ultrasonography of entheseal insertions in the lower limb in spondyloarthropathy. Ann Rheum Dis 2002;61:905-10.

[5] De Miguel E, Cobo T, Muñoz-Fernández S, et al. Validity of enthesis ultrasound assessment in spondylarthropathy. Ann Rheum Dis 2009;68:169-74.

[6] Wakefield RJ, D'Agostino MA, Iagnocco A, et al. The OMERACT Ultrasound Group: status of current activities and research directions. J Rheumatol 2007;34:848-51.

[7] McGonagle D, Khan MA, Marzo-Ortega H, et al. Enthesitis in spondylarthropathy. Curr Opin Rheumatol 1999;11:244-50.
[8] Jacobs JC. Spondylarthropathy and enthesopathy. Arch Intern Med 1983;143:103-7.

[9] McGonagle D, Gibbon W, Emery P. Classification of inflammatory arthritis by enthesitis. Lancet 1998;352:1137-40.

Annamaria Iagnocco ${ }^{\mathrm{a}, *}$ Antonio Spadaro ${ }^{\mathrm{a}}$

Antonio Marchesoni ${ }^{b}$

Alberto Caulic

Orazio De Lucia ${ }^{\mathrm{b}}$

Alessandra Gabba ${ }^{c}$

Silvia Takanen ${ }^{\mathrm{a}}$

Monica Montepaone ${ }^{a}$

Fabio Massimo Perrotta ${ }^{a}$

Maria Antonietta D'Agostino ${ }^{d}$

Alessandro Mathieu $^{\mathrm{c}}$ Guido Valesini ${ }^{\mathrm{a}}$

a Rheumatology Unit, Dipartimento di Medicina Interna e Specialità Mediche, Sapienza Università di Roma, Policlinico Umberto $1^{\circ}$, Viale del Policlinico 155, 00161 Rome, Italy

${ }^{\mathrm{b}}$ Rheumatology Department, Istituto Ortopedico Gaetano Pini, Milano, Italy

${ }^{\mathrm{c}}$ Rheumatology Department, Università di Cagliari, Cagliari, Italy

d Department of Rheumatology, université Paris Ouest-Versailles-Saint-Quentin-en-Yvelines, hôpital Ambroise-Paré, AP-HP, 92100 Paris, France

* Corresponding author. Tel.: +39 0649974637 ; fax: +390649974642

E-mail address: annamaria.iagnocco@uniroma1.it

(A. Iagnocco)

2 October 2011

Available online 26 November 2011

doi:10.1016/j.jbspin.2011.10.005

Rheumatoid arthritis, alveolar echinococcosis, and rituximab: A case report

\section{A R T I C L E I N F O}

\section{Keywords:}

Alveolar echinococcosis

Rituximab

Rheumatoid arthritis

\footnotetext{
is The first two authors contributed equally to this manuscript
} 